\title{
Perennial Grasses as a Substrate for Bioethanol Production
}

\author{
Merlin RAUD ${ }^{1 *}$, Timo KIKAS ${ }^{2}$ \\ ${ }^{1,2}$ Institute of Technology, Estonian University of Life Sciences, Kreutzwaldi 56, 51014 Tartu, Estonia
}

\begin{abstract}
One of the possible choices as a biomass for lignocellulosic bioethanol production are different perennial grasses. Cultivating this type of biomass has many advantages in terms of natural diversity and landscape protection. In this study, mixture of red clover and timothy grass was used as a feedstock to investigate its potential as a substrate for bioethanol production. Traditional three step bioethanol production process was used in combination with NED pretreatment. The results show at all pretreatment temperatures similar glucose concentrations and hydrolysis efficiencies, which varied from 4.3 to $5.1 \mathrm{~g} / \mathrm{l}$ and $15.2 \%$ to $17.7 \%$, respectively. The ethanol yield, on the other hand, decreased as the pretreatment temperature increased. However, the mass balance revealed that when using this kind of feedstock, 3.3-4.0 $\mathrm{g}$ ethanol could be produced from $100 \mathrm{~g}$ of biomass. The overall efficiency and yield of the process was lower than expected due to pretreatment, which might not have been suitable for soft biomass.
\end{abstract}

Keywords - Bioethanol; biomass; perennial grass; pretreatment

\section{INTRODUCTION}

We are living in times where we are moving from fossil fuel based economy to an economy based on bioresources. In transportation sector, by 2020 there must be $10 \%$ share of biofuels, and by 2030 this is further increased. Part of the used transportation fuels must be advanced biofuels produced from non-food biomass like lignocellulosic biomass [1], [2]. The lignocellulosic biomass can come from residues of agricultural and forestry sectors and from dedicated energy crops no longer required for food production [3].

Recently, much attention has been paid to bioenergy production from different biomass sources and thereby, perennial grasses have gained attention as a biomass source for biofuel production. Perennial plants are grown on degraded lands that are no longer suitable for agricultural use and thereby, their use for biofuel production can decrease the competition with foodcrops [4]. In addition, these plants can be used as cover crops in a crop rotation since they can increase soil C and $\mathrm{N}$ storage, reduce the potential for $\mathrm{N}$ leaching and $\mathrm{N}$ fertilization rates [5]. Moreover, grasslands are recognized for their role in providing beneficial ecosystem services and wider benefits to society. These include the food and bioenergy production, biodiversity of grassland ecosystems, landscape and aesthetic values, climate regulation, soil and water protection at local and regional scales, etc. [6].

The traditional bioethanol production process consists of three process steps - pretreatment, enzymatic hydrolysis, and fermentation. The pretreatment step is used to open the biomass structure and make the cellulose accessible for enzymatic hydrolysis. In the enzymatic hydrolysis,

* Corresponding author.

E-mail address: Merlin.Raud@emu.ee 
the cellulose polymer is hydrolysed into glucose monomers. Hydrolysis is finally followed by fermentation, where the glucose is fermented into ethanol [8].

The pretreatment is one of the most important steps to gain effective bioethanol production process. Due to tight packaging of cellulose in lignin and hemicellulose cover, the cellulose is difficult to access and this makes the production process inefficient. The pretreatment enables to increase the process efficiency by breaking down lignin and hemicellulose cover and thereby, making cellulose more accessible for further processing [7]. Various pretreatment methods have been proposed and studied. As the biomass composition and pretreatment methods differ, individual approach for selection of suitable processing methods is needed for different biomasses. The choice of a suitable method depends on the biomass characteristics and the following process steps [8].

In this study, combined physio-chemical method, nitrogen explosive decompression (NED) pretreatment was used [8]-[10]. The method is based on applying high pressure and temperature to biomass. The pressure is increased by adding $\mathrm{N}_{2}$ gas to the biomass. Autohydrolysis is initiated by the temperature and the nitrogen molecules will penetrate into the cells of biomass. If the pressure is decreased in an explosive manner, the dissolved nitrogen gas expands and opens the cellulosic structure of the biomass [8]-[10].

The NED pretreatment method has been used to pretreat agricultural residues, like barley straw [9], [11] and floodplain meadow hay [10], but also for processing municipal greening waste [12] and timber residues from different wood species. However, it has not been used for pretreatment of perennial grasses and other dedicated feedstocks. In addition, little research has been done on using perennial grasses as a bioethanol feedstock.

The goal of this study was to investigate the use of mixed perennial grasses - red clover and timothy grass as a feedstock and its potential as a substrate for bioethanol production. Traditional three step bioethanol production process was used with NED method for pretreatment of biomass. Samples from various process stages were collected and analysed to see the suitability of this pretreatment to perennial grasses. The collected data was used to calculate the mass and energy balances to quantify the material flows and assess different technological routes for effective bioethanol production.

\section{MATERIALS AND METHODS}

\subsection{Biomass}

Mixture of red clover (Trifolium pratense) and timothy grass (Phleum pratense L.) with an average red clover content was $42 \%$ was used as a biomass in all experiments. The samples were dried to gain moisture content less than $10 \%$ and ground with Cutting Mill SM 100 comfort (Retsch $\mathrm{GmbH}$, Germany) to gain particle-size $3 \mathrm{~mm}$ or less.

\subsection{Production Route Design}

To evaluate in which process step solid and liquid separation would give biggest effect, the bioethanol production from biomass was evaluated using two different routes, as shown in Fig. 1. In both routes, the three-step bioethanol production process was used. In case of route 1, the solid and liquid fractions were separated after enzymatic hydrolysis and only the liquid part was used in ethanol production process. In case of route 2 , the biomass slurry was used in fermentation process without solid and liquid separation. After hydrolysis, yeast (Saccharomyces cerevisiae) was added to liquid part or to biomass slurry in fermentation step to study the bioethanol production potential. 


\subsection{Explosive Decompression Pretreatment}

The instrumentation and working principles of ED pretreatment method are described in detail in previous publications [9], [10], [13]. $700 \mathrm{ml}$ of distilled water was added to $100 \mathrm{~g}$ of dried and milled biomass and mixed thoroughly to gain homogenous biomass slurry. The pretreatment was conducted at temperatures of $125-175^{\circ} \mathrm{C} \pm 3{ }^{\circ} \mathrm{C}$ according to previously described methods [9], [10], [13].

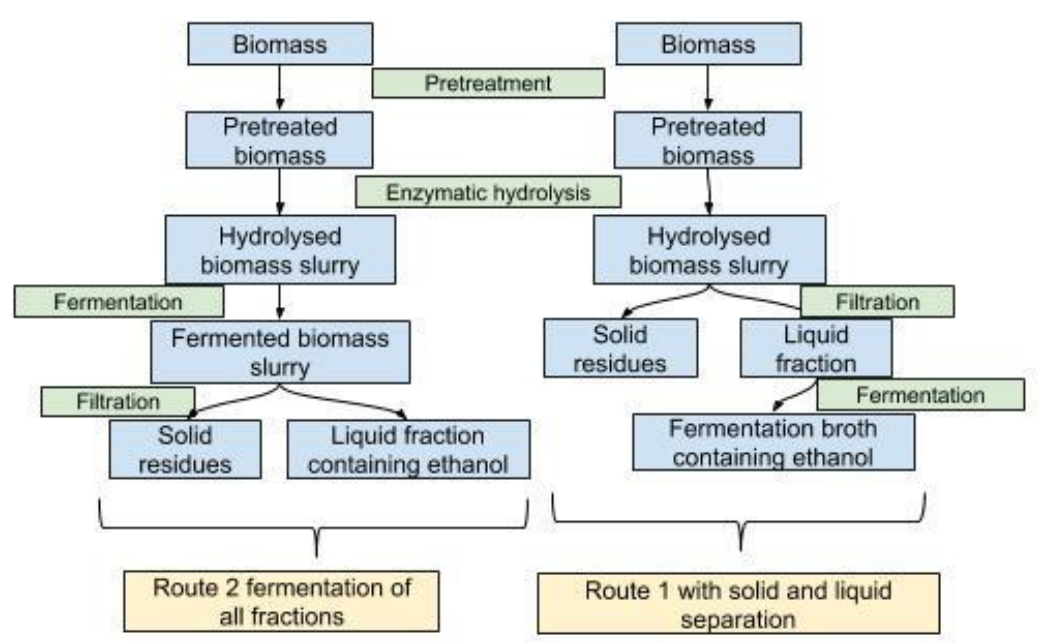

Fig. 1. A flow chart of the studied routes of biomass for biofuel production.

\subsection{Enzymatic hydrolysis and fermentation}

Enzymatic hydrolysis with enzyme complex was used to convert cellulose to glucose. Distilled water and enzyme were added to the pretreated biomass in order to gain the final volume of the mixture $1000 \mathrm{ml}$. Enzyme mixture (Accellerase 1500 from DuPont $\AA$; $30 \mathrm{FPU} \mathrm{g}^{-1}$ cellulose) was added to biomass suspension at a ratio of $0.3 \mathrm{ml}$ per $\mathrm{g}$ of biomass. Hydrolysis lasted for 24 hours at a temperature of $50{ }^{\circ} \mathrm{C}$ under constant stirring in rotating shaker/incubator $\left(250 \mathrm{~min}^{-1}\right)$ (Unimax 1010, Heidolph Instruments GmbH \& Co.KG) [13].

Vacuum filtration was used to separate the liquid part from the solid part and only the liquid part was used for fermentation. $1.0 \mathrm{~g}$ of yeast Saccharomyces cerevisiae was added to the $200 \mathrm{ml}$ of liquid phase to start the fermentation process. The fermentation process was carried out at room temperature $\left(22^{\circ} \mathrm{C} \pm 1{ }^{\circ} \mathrm{C}\right.$ ) for 7 days under low oxygen conditions in $250 \mathrm{~mL}$ glass bottles sealed with a fermentation tube [13].

\subsection{Biomass analysis}

The solid and liquid parts of the biomass mixture were weighed before and after pretreatment and enzymatic hydrolysis. From each step corresponding samples were taken for analysis. The initial biomass but also solid biomass gained after pretreatment and enzymatic hydrolysis was dried and milled for further analysis. 
Dry matter content was analysed with a moisture analyser Kern MLS-D (KERN \& SOHN $\mathrm{GmbH}$ ) and ash content according to NREL Technical Report NREL/TP-510-42622 [14].

The biomass was submitted to an acid detergent fiber (ADF), neutral detergent fiber (NDF) and acid detergent lignin (ADL) tests to determine the contents of cellulose, hemicellulose and lignin using ANKOM 2000 analyser (ANKOM Technology, USA).

The glucose and ethanol concentrations were determined using HPLC Shimadzu Prominence-i LC-2030 3D Plus and detector Shimadzu RID-20A. The analytical separation of glucose was accomplished with the columns RezexTM RPM-Monosaccharide Pb+2 and RezexTM RHMMonosaccharide $\mathrm{H}+$, which were arranged in sequence. The column oven temperature was $85{ }^{\circ} \mathrm{C}$ and the detector temperature $60{ }^{\circ} \mathrm{C}$. Autoclaved and degassed distilled water was used as a mobile phase at a flow rate of $0.8 \mathrm{~mL} / \mathrm{min}$. For the sugar quantification, a calibration range from $50 \mathrm{mg} / \mathrm{L}$ to $2000 \mathrm{mg} / \mathrm{L}$ was chosen. The injection volume of the samples was $20 \mu \mathrm{L}$.

The column RezexTM ROA-Organic Acid H+ was used for the detection of ethanol. The column oven and detector temperature were set to $50{ }^{\circ} \mathrm{C}$. Autoclaved and degassed $5 \mathrm{mM} \mathrm{H}_{2} \mathrm{SO}_{4}$ was used as mobile phase at a flow rate of $0.5 \mathrm{~mL} / \mathrm{min}$. The calibration ranged from $200 \mathrm{mg} / \mathrm{L}$ to $20 \mathrm{~g} / \mathrm{L}$ for acetic acid and ethanol quantification. The sample injection volume was $10 \mu \mathrm{L}$. All measurements were conducted in triplicate and average and standard deviations were calculated.

\section{RESULTS AND DISCUSSION}

\subsection{Biomass}

The relative proportion of cellulose, hemicellulose, lignin, ash, and moisture is usually used to characterize the biomass. The chemical composition of biomass varies according to its cultivation location and method but also from harvesting season [15]. Previous research has indicated that energy crops for ethanol production should be selected based on their cellulose content since ethanol yield per $\mathrm{kg}$ of biomass has been shown to be directly proportional to the cellulose content in the energy crop [16]. As seen in Table 1, the selected biomass had cellulose content of $25.8 \%$ and rather low hemicellulose and lignin contents. Compared to cereal straws reported by different authors [11], [17]-[19], the cellulose content in the biomass was lower than in agricultural residues however, it can be considered a suitable raw material for bioethanol production.

TABLE 1. COMPOSITION OF BIOMASS

\begin{tabular}{lcccccc}
\hline Sample & Ash, $\boldsymbol{\%}$ & ADF, \% & NDF, \% & Lignin, $\%$ & Cellulose, $\boldsymbol{\%}$ & Hemicellulose, $\boldsymbol{\%}$ \\
\hline Biomass & 6.4 & $31.0 \pm 0.5$ & $49.3 \pm 2.8$ & $5.1 \pm 0.4$ & $25.8 \pm 0.2$ & $18.4 \pm 2.9$ \\
\hline
\end{tabular}

\subsection{Hydrolysis}

The pretreated biomass was used in a conventional three-step bioethanol production process, where enzymatic hydrolysis followed the pretreatment. To assess the effect of pretreatment, the glucose concentrations were measured before and after enzymatic hydrolysis.

In Fig. 2, hydrolysis efficiencies and glucose concentrations in hydrolysis mixture after hydrolysis has been presented. The glucose concentrations in hydrolysis mixture varies from 4.3 to $5.1 \mathrm{~g} / \mathrm{l}$. The lowest concentration was gained when biomass was pretreated at $150{ }^{\circ} \mathrm{C}$ while the highest concentration was measured when biomass was pretreated at $125^{\circ} \mathrm{C}$, however no statistical difference was found in results in case of different pretreatment temperatures (T-test $p>0.05$ ). The hydrolysis efficiencies varied between $15.2 \%$ and $17.7 \%$. In previous studies when barley hay was used with NED pretreatment the glucose yield and hydrolysis efficiency increased 
with the increase in pretreatment temperature. The hydrolysis efficiency and glycose yield increased twofold when pretreatment temperature was increased from $100{ }^{\circ} \mathrm{C}$ to $175^{\circ} \mathrm{C}$ [20]. As the glucose yield is rather similar in case of all pretreatment temperatures, it would be reasonable to use lower pretreatment temperature since the process consume less energy for heating the biomass.

The small effect of pretreatment and low hydrolysis efficiency can be explained by the biomass composition and harvesting time. The biomass contains low NDF and hemicellulose values characteristic to biomass collected in summer. The NDF represents the most of the structural components in plant cell - mainly of lignin, cellulose and hemicellulose, which makes the biomass less biodegradable [21]. In previous studies, it has been shown that the cellulose and lignin content of the biomass rises with maturity, the plant cells increase, which causes the stalk to harden and this also decreases the hydrolysis efficiency [22]. The low values of hemicellulose and lignin indicate that the structure of biomass is softer than in most agricultural wastes previously used with this pretreatment method. The explosive decompression pretreatment method might not be suitable in case of soft cell structure of the biomass. During pretreatment, this kind of biomass cell acts in an elastic manner - stretching and contracting without being destructed and opened for the continued processing.

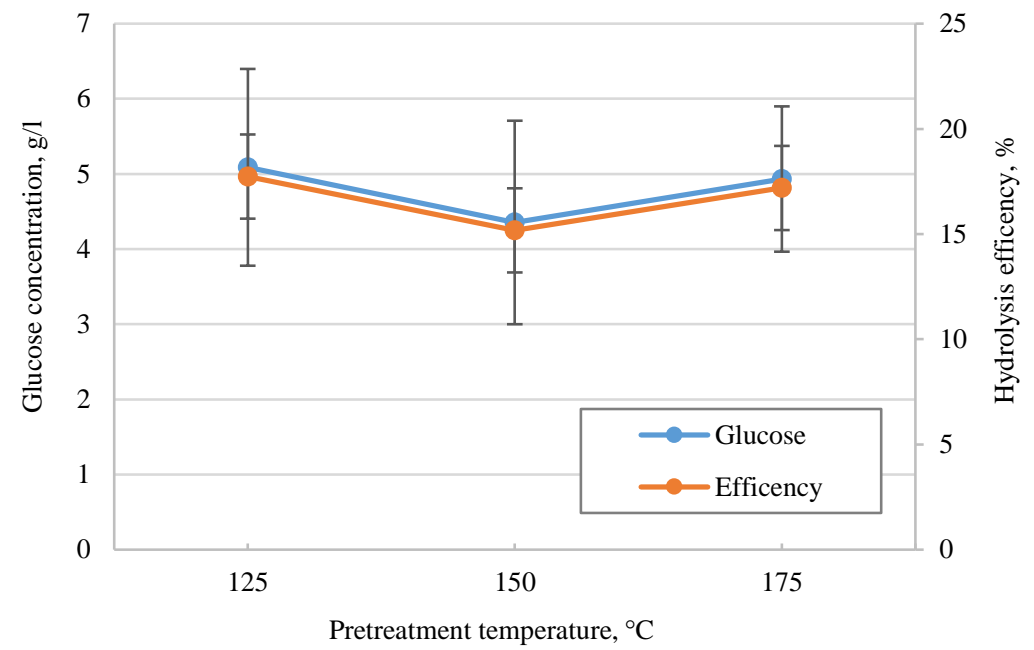

Fig. 2. Hydrolysis efficiency and glucose concentration in hydrolysis mixture in case of different pretreatment temperatures.

\subsection{Fermentation}

Fermentation was carried out with yeast Saccharomyces cerevisiae using two different approaches to evaluate in which process step solid and liquid separation would give biggest effect in terms of final ethanol yield. Ethanol concentrations in the media after fermentation have been shown in Fig. 3.

The results indicate that higher ethanol concentrations were gained when both, solid and liquid fractions were used in the fermentation. In this case, 5-13\% higher ethanol concentrations were gained compared to fermenting only the liquid fraction. Lower ethanol concentrations, when only liquid fraction was fermented, can be caused by the continuing hydrolysis of cellulose in the solid fraction or hydrolysis of oligomers. The solid fraction still contains $23-28 \%$ of unused cellulose 
which were partly hydrolysed into glucose monomers during the fermentation. This increased the concentration of available sugars and enabled to gain higher final ethanol concentrations. The continuing hydrolysis of cellulose during fermentation causes also the rise in fermentation efficiency over $100 \%$.

In both fermentation approaches, the ethanol yields decrease as the pretreatment temperature increase. Statistically significant differences were found between results of ethanol concentration after pretreatment at $125^{\circ} \mathrm{C}$ and $175^{\circ} \mathrm{C}$ (two-way ANOVA multiple comparison test). When the biomass and liquid is fermented jointly, the final ethanol concentration decreases $29.1 \%$ as the pretreatment temperature is increased from $125^{\circ} \mathrm{C}$ to $175^{\circ} \mathrm{C}$. For fermentation of only liquid fraction, the decrease in ethanol concentration is $23.8 \%$ with the rise in pretreatment temperature. Similar tendency have been reported in previous papers when the same pretreatment method was used with barley hay or urban greening waste [9], [11]-[13], [20]. Earlier papers have also shown that increase in the pretreatment temperature to $175^{\circ} \mathrm{C}$ or higher than that is not recommended, as the formation of fermentation inhibiting compounds at higher temperatures decreases the ethanol yields even if the glucose is still present in the sample [9].

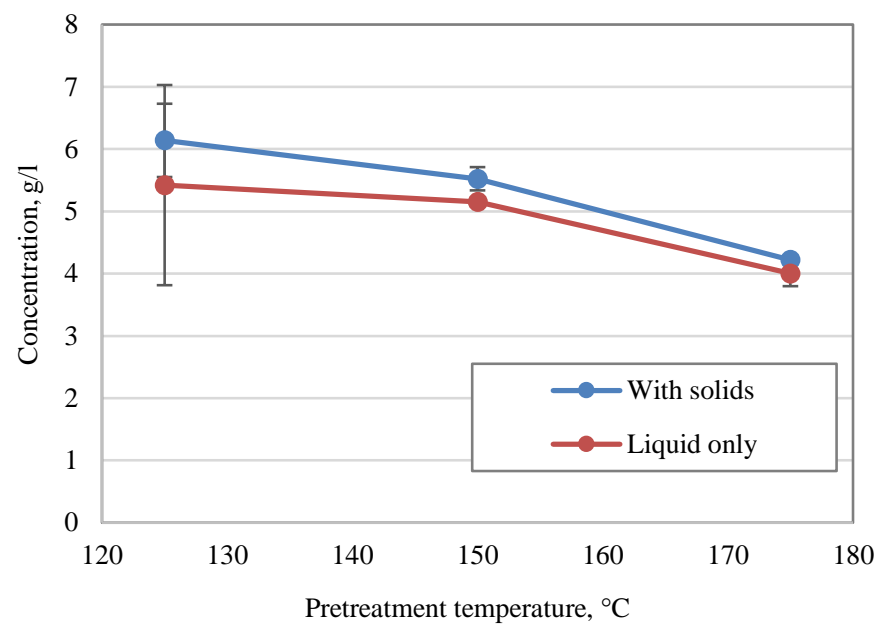

Fig. 3. Ethanol concentration after fermentation steps in case of different pretreatment temperatures using two fermentation approach - fermentation of liquids with solids and fermentation of liquids where solid fraction has been removed.

\subsection{Mass Balance}

The liquid and solid phases from all process stages were weighed, fiber analysis of all solid samples was conducted, and glucose and ethanol concentrations were measured from liquid samples after hydrolysis and fermentation stages, respectively. Based on collected data, the mass balance of bioethanol production process was calculated and mass flow charts were prepared. Fig. 4 and Fig. 5 present the mass balance data of the two selected approaches.

From Fig. 4 and Fig. 5 it can be seen that there is a loss in dry mass during the pretreatment. The mass loss is caused by the dissolution of biomass components during pretreatment and also partially due to the evaporation of moisture during explosive decompression. During pretreatment, cellulose and lignin remained in the biomass while hemicellulose was partially removed. After pretreatment, 9.2-16.0 $\mathrm{g}$ of hemicellulose remained in the biomass from initial $18.3 \mathrm{~g}$. The hemicellulose dissolution was larger at higher pretreatment temperatures. Similar effect with 
hemicellulose dissolution was reported in earlier papers when barley hay was used [20]. Since the NED pretreatment method is analogous to steam explosion method, we can assume that similar processes are taking place with the biomass during the pretreatment. The high temperature during pretreatment initiates autohydrolysis, which causes hemicellulose hydrolysis and lignin transformation [23], [24]. Therefore, decrease in hemicellulose content can be seen as the pretreatment temperature is increased.

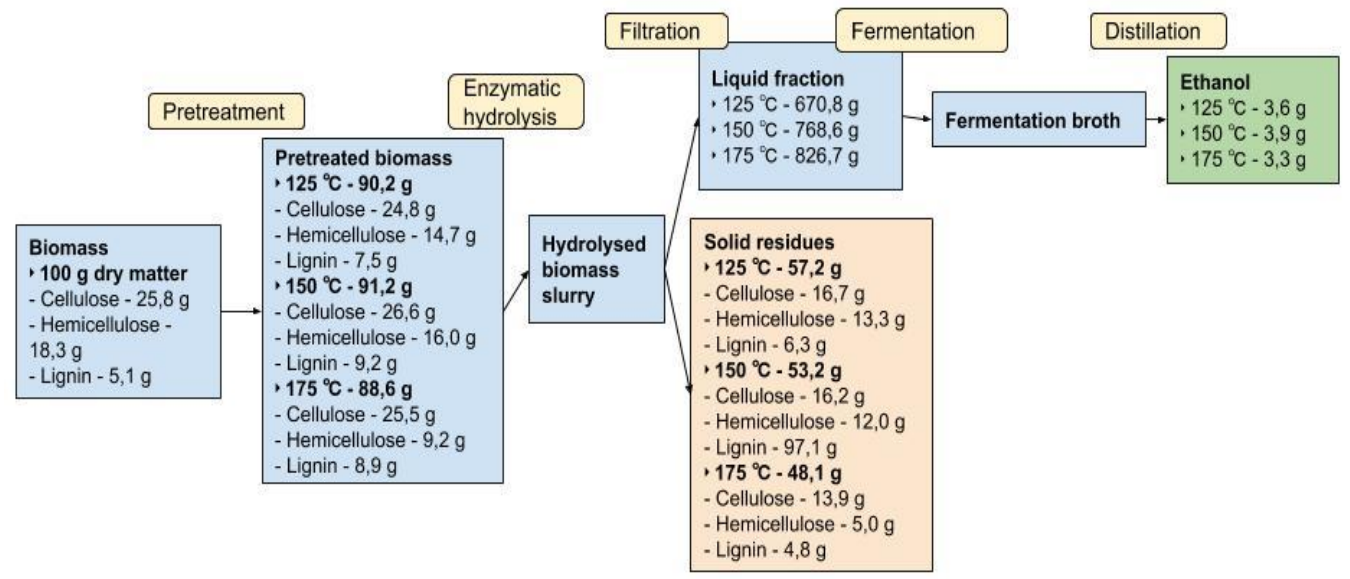

Fig. 4. Mass balance of bioethanol production process when different pretreatment temperatures were used and solid and liquid parts of hydrolysis slurry were separated after hydrolysis and only liquid fraction was used for fermentation.

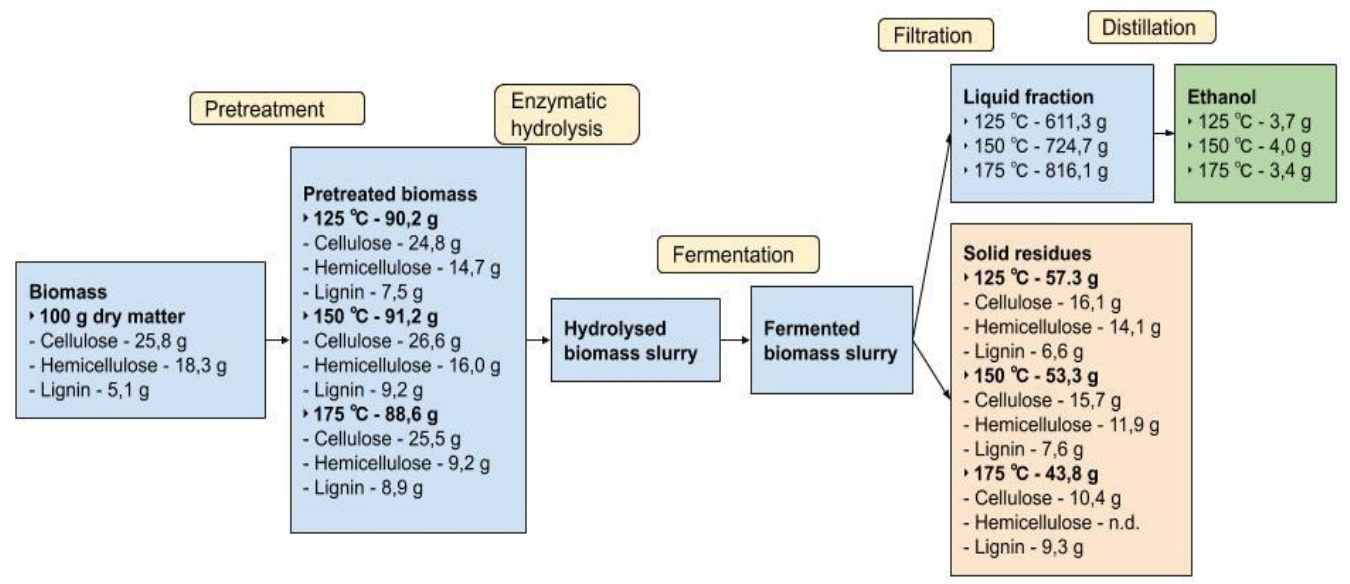

Fig. 5. Mass balance of bioethanol production process when different pretreatment temperatures were used and solid and liquid parts of hydrolysis slurry was fermented together.

When liquid and solid fractions were separated after hydrolysis, 57.2-48.1 $\mathrm{g}$ of solid residues remained (Fig. 4). The solid residues still contained 12-14 g of cellulose, which remained unused in the hydrolysis process. This shows that either pretreatment or enzymatic hydrolysis process was ineffective. If due to the ineffective pretreatment the access to cellulose fibrils is not achieved and it will not be hydrolysed into sugars but remains in the residual biomass. Additionally, hydrolysis 
efficiency can be low due to the low enzyme activity or enzyme unsuitability for this biomass or hydrolysis conditions. Similar results were reported in study with native sorghum pretreated with acids and in that case from $37.9 \mathrm{~g}$ of cellulose in the initial biomass, $18.4 \mathrm{~g}$ remained in the residual biomass after the enzymatic hydrolysis [25].

When the solid and liquid fractions were separated after fermentation step, the amount and composition of solid fraction (Fig. 5) were similar to those when separation was conducted after hydrolysis step. Small difference was noted at pretreatment temperature of $175^{\circ} \mathrm{C}$, where less residues were measured and the cellulose content in it was also smaller $-10.4 \mathrm{~g}$ of cellulose in $43.8 \mathrm{~g}$ residual biomass compared to $13.9 \mathrm{~g}$ cellulose in $48.1 \mathrm{~g}$ of residual biomass when separation was done after hydrolysis.

In both approaches, liquid and solid fractions were separated by filtration and weighed. Up to $8 \%$ more liquid fraction was separated when filtration was conducted after hydrolysis. Although more liquid fraction was gained, the final ethanol yield in both cases differs only by $0.1 \mathrm{~g}$ since the ethanol concentration in this case was smaller than in the samples, where solid and liquid separation was conducted after fermentation. In case of both approaches, the overall ethanol yield is smaller than reported earlies using this approach due to low efficiency of pretreatment [20], [26].

\section{Conclusions}

Mixture of red clover and timothy grass was used as a feedstock to investigate its potential as substrate for bioethanol production. Traditional three step bioethanol production process was used in combination with NED pretreatment. The results show at all pretreatment temperatures similar glucose concentrations and hydrolysis efficiencies, which varied from 4.3 to $5.1 \mathrm{~g} / \mathrm{l}$ and $15.2 \%$ to $17.7 \%$, respectively. This differs from earlier studies with this pretreatment method as the results are similar in entire pretreatment temperature range and the increase in temperature did not have positive effect. Fermentation efficiencies exceeded $100 \%$ due to sugars available in other forms but total ethanol yield, on the other hand, decreased as the pretreatment temperature increased. The mass balance revealed that, when using this kind of feedstock, 3.3-4.0 g ethanol could be produced from $100 \mathrm{~g}$ of biomass and both approaches used in fermentation gave similar results.

\section{ACKNOWLEDGEMENT}

We gratefully acknowledge the financial support of the European Regional Development Fund via the Mobilitas Pluss (project MOBERA2) of the Estonian Research Council. We thank Narasinha Shurpali for providing the biomass samples.

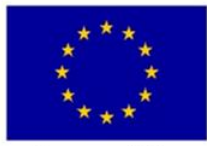

European Union European Regional European Regional
Development Fund

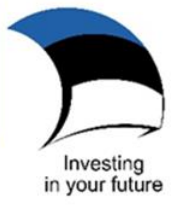

\section{REFERENCES}

[1] Directive 2015/1513/EU of the European Parliament and of the Council of 9 September 2015 amending Directive 98/70/EC relating to the quality of petrol and diesel fuels and amending Directive 2009/28/EC on the promotion of the use of energy from renewable sources. Official Journal of the European Union 2015: L 239/1.

[2] Directive 2018/2001/EU of the European Parliament and of the Council of 11 December 2018 on the promotion of the use of energy from renewable sources. Official Journal of the European Union 2018: L 328/82.

[3] Ghosh S., Chowdhury R., \& Bhattacharya P. Sustainability of cereal straws for the fermentative production of second generation biofuels: A review of the efficiency and economics of biochemical pretreatment processes. Applied Energy 2017:198:284-298. https://doi.org/10.1016/j.apenergy.2016.12.091 
[4] Chang F.-C., Lin L.-D., Ko C.-H., Hsieh H.-C., Yang B.-Y., Chen W.-H., \& Hwang W.-S. Life cycle assessment of bioethanol production from three feedstocks and two fermentation waste reutilization schemes. Journal of Cleaner Production 2017:143:973-979. https://doi.org/10.1016/j.jclepro.2016.12.024

[5] Sainju U. M., Singh H. P., \& Singh B. P. Soil Carbon and Nitrogen in Response to Perennial Bioenergy Grass, Cover Crop and Nitrogen Fertilization. Pedosphere 2017:27(2):223-235. https://doi.org/10.1016/S10020160(17)60312-6

[6] Kizeková M., Hopkins A., Kanianska R., Makovníková J., Pollák Š., \& Pálka B. Changes in the area of permanent grasslands and its implications for the provision of bioenergy: Slovakia as a case study. Grass Forage Science 2018:73:218-232. https://doi.org/10.1111/gfs.12333

[7] Bhutto A. W., Qureshi K., Harijan K., Abro R., Abbas T., Bazmi A. A., Karim S., \& Yu G. Insight into progress in pre-treatment of lignocellulosic biomass. Energy 2017:122:724-745. https://doi.org/10.1016/j.energy.2017.01.005

[8] Raud M., Kikas T., Sippula O., \& Shurpali N. J. Potentials and challenges in lignocellulosic biofuel production technology. Renewable and Sustainable Energy Reviews 2019:111:44-56. https://doi.org/10.1016/j.rser.2019.05.020

[9] Raud M., Olt J., \& Kikas T. $\mathrm{N}_{2}$ explosive decompression pretreatment of biomass for lignocellulosic ethanol production. Biomass and Bioenergy 2016:90:1-6. https://doi.org/10.1016/j.biombioe.2016.03.034

[10] Tutt M., Raud M., Kahr H., Pointner M., Olt J., \& Kikas T. Nitrogen explosion pretreatment of lignocellulosic material for bioethanol production. Energy Sources Part A: Recovery, Util. Environ. Eff. 2016: 38(12):1785-1789. https://doi.org/10.1080/15567036.2014.1002950

[11] Raud M., Krennhuber K., Jäger A., \& Kikas T. Nitrogen explosive decompression pre-treatment: An alternative to steam explosion. Energy 2019:177:175-182. https://doi.org/10.1016/j.energy.2019.04.071

[12] Raud M., Mitt M., Oja T., Olt J., Orupõld K., \& Kikas T. The utilisation potential of urban greening waste: Tartu case study. Urban Forestry \& Urban Greening 2017:21:96-101. https://doi.org/10.1016/j.ufug.2016.11.014

[13] Raud M., Rooni V., Kikas T., Explosive decompression pretreatment: Nitrogen vs. compressed air. Agronomy Research 2016:14(2):569-578.

[14] Sluiter A., Hames B., Ruiz R., Scarlata C., Sluiter J., \& Templeton D. Determination of Ash in Biomass. Laboratory Analytical Procedure (LAP). Technical Report NREL/TP-510-42622, 2005.

[15] Han M., Kang K. E., Kim Y., \& Choi G.-W. High efficiency bioethanol production from barley straw using a continuous pretreatment reactor. Process Biochemistry 2013:48(3):488-495. https://doi.org/10.1016/j.procbio.2013.01.007

[16] Kikas T., Tutt M., Raud M., Alaru M., Lauk R., \& Olt J. Basis of Energy Crop Selection for Biofuel Production: Cellulose vs. Lignin. International Journal of Green Energy 2016:13(1):49-54. https://doi.org/10.1080/15435075.2014.909359

[17] Balat M. Production of bioethanol from lignocellulosic materials via the biochemical pathway: A review. Energy Conversion and Management 2011:52(2):858-875. https://doi.org/10.1016/j.enconman.2010.08.013

[18] Talebnia F., Karakashev D., \& Angelidaki I. Production of bioethanol from wheat straw: An overview on pretreatment, hydrolysis and fermentation. Bioresource Technology 2010:101(13):4744-4753. https://doi.org/10.1016/j.biortech.2009.11.080

[19] Conde-Mejía C., Jiménez-Gutiérrez A., \& El-Halwagi M. A comparison of pretreatment methods for bioethanol production from lignocellulosic materials. Process Safety and Environmental Protection 2012:90(3):189-202. https://doi.org/10.1016/j.psep.2011.08.004

[20] Raud M., Rooni V., \& Kikas T. The Efficiency of Nitrogen and Flue Gas as Operating Gases in Explosive Decompression Pretreatment. Energies 2018:11(8):2074. https://doi.org/10.3390/en11082074

[21] Heinsoo K., Melts I., Sammul M., \& Holm B. The potential of Estonian semi-natural grasslands for bioenergy production. Agriculture, Ecosystems \& Environment 2010:137(1-2):86-92. https://doi.org/10.1016/j.agee.2010.01.003

[22] Tutt M., Kikas T., \& Olt J. Influence of harvesting time on biochemical composition and glucose yield from hemp. Agronomy Research 2013:11(1):215-220.

[23] Samuel R., Cao S., Das B. K., Hu, F., Pu, Y., \& Ragauskas, A. J. Investigation of the fate of poplar lignin during autohydrolysis pretreatment to understand the biomass recalcitrance. RSC Adv. 2013:3(16):5305-5309. https://doi.org/10.1039/c3ra40578h

[24] Oliveira F. M. V., Pinheiro I. O., Souto-Maior A. M., Martin C., Gonçalves A. R., \& Rocha G. J. M. Industrial-scale steam explosion pretreatment of sugarcane straw for enzymatic hydrolysis of cellulose for production of second generation ethanol and value-added products. Bioresource Technology 2013:130:168-173. https://doi.org/10.1016/j.biortech.2012.12.030

[25] Akanksha K., Sukumaran R. K., Pandey A., Rao S. S., \& Binod P. Material balance studies for the conversion of sorghum stover to bioethanol. Biomass and Bioenergy 2016:85:48-52. https://doi.org/10.1016/j.biombioe.2015.11.027

[26] Aunina Z., Bazbauers G., \& Valters K. Feasibility of Bioethanol Production From Lignocellulosic Biomass. Environmental and Climate Technologies 2010:4(1):11-15. https://doi.org/10.2478/v10145-010-0011-x 